\title{
Involvement of $\beta$-Glucans in the Wide-Spectrum Antimicrobial Activity of Williopsis saturnus var. mrakii MUCL 41968 Killer Toxin
}

\author{
Cyril Guyard, ${ }^{1,2}$ Eric Dehecq, ${ }^{3}$ Jean-Pierre Tissier, ${ }^{4}$ Luciano Polonelli, ${ }^{5}$ Eduardo Dei-Cas, ${ }^{2,6,7}$ \\ Jean-Charles Cailliez, ${ }^{2,3,6}$ and Franco D. Menozzi ${ }^{1,2}$ \\ ${ }^{1}$ INSERM U447, Mécanismes Moléculaires de la Pathogénie Microbienne, Institut Pasteur de Lille, \\ Institut de Biologie de Lille, France \\ ${ }^{2}$ IFR 17, Institut Pasteur de Lille, Lille, France \\ ${ }^{3}$ Laboratoire Environnement et Santé, Université Catholique de Lille, Lille, France \\ ${ }^{4}$ INRA Centre de Recherche de Lille, Villeneuve d'Ascq, France \\ ${ }^{5}$ Dipartimento di Patologia e Medicina, Sezione di Microbiologia, Università degli Studi di Parma, \\ Parma, Italy \\ ${ }^{6}$ Laboratoire d'Ecologie du Parasitisme, Institut Pasteur de Lille, Lille, France \\ ${ }^{7}$ Centre Hospitalier et Faculté de Médecine, Lille, France \\ Accepted September 26, 2002
}

\begin{abstract}
Background: Williopsis saturnus var. mrakii MUCL 41968 secretes a $85-\mathrm{kDa}$ glycoprotein killer toxin (WmKT) that displays a cytocidal activity against a wide range of microorganisms, making WmKT a promising candidate for the development of new antimicrobial molecules. Although the killing mechanism of WmKT is still unknown, the toxin was recently proposed to bind to the surface of sensitive microorganisms through the recognition of $\beta$-glucans. Indeed, Saccharomyces cerevisiae strains sensitive to the toxin become resistant when mutated in their $\beta$-glucan synthesis pathway.

Materials and Methods: To investigate the interaction of WmKT with $\beta$-glucans, we examined in agar diffusion assays the WmKT activity in the presence of enzymes displaying $\beta$-glucanase activity. The toxin activity was also investigated using spheroplasts derived from sensitive yeast cells. The hydrolytic activity of WmKT was studied using specific glucosidase inhibitors as well as various sugar molecules covalently linked to $p$-nitrophenyl as potential substrates. Finally, the ultrastructural modifications induced by WmKT activity on sensitive yeasts were assessed by scanning electron microscopy.
\end{abstract}

Results: The data reported here support the hypothesis that WmKT binds to sensitive cells using surface-exposed $\beta$-glucans. Indeed $\beta$-glucanase exerts an antagonistic effect on WmKT activity and spheroplasts derived from WmKT-sensitive yeast cells are shown to be resistant to WmKT, suggesting that cell wall $\beta$-glucans are required for WmKT lethal effect. Because WmKT exhibits amino acid sequence similarities with proteins suspected to be glucanase, we also investigated the effect of castanospermine, a potent glucosidase inhibitor, on WmKT activity. Castanospermine completely abolished WmKT killer activity as well as its hydrolytic enzymatic activity against $p$-nitrophenyl $\beta$-D-glucopyranoside. The scanning electron microscopy analysis of sensitive yeast cells treated with the toxin reveals that WmKT causes cell wall modifications similar to those observed with zymolyase.

Conclusion: The results reported in this study show that WmKT activity requires an interaction between the mycocin and the cell wall $\beta$-glucans. Moreover, they indicate that WmKT acts on sensitive yeast cells through a hydrolytic activity directed against cell wall $\beta$-glucans that disrupts the yeast cell wall integrity leading to death.

\section{Introduction}

In the past decade, a significant increase in the prevalence of resistance to antibacterial and antifungal agents has been reported $(1,2)$. The emergence of infectious agents resistant to conventional treatments has highlighted the need for novel antimicrobial agents. Among the new potential antimicrobial

Address correspondence and reprint requests to: Cyril Guyard, INSERM U447, Mécanismes Moléculaires de la Pathogénie Microbienne, Institut Pasteur de Lille, 1 rue Calmette, BP245, 59019 Lille Cedex, France. Phone: +33.320.87.11.53;

fax: +33.320.87.11.58; e-mail: Cyril.Guyard@pasteur-lille.fr. molecules, specific yeast mycocins (killer toxins) represent promising candidates because they display wide spectra of activity $(3,4)$. Because of its particularly wide spectrum of activity, the killer toxin (WmKT) produced by Williopsis saturnus var. mrakii MUCL 41968, previously reported as a Pichia anomala K36 killer toxin (5), has been extensively described. WmKT antimicrobial activity has been demonstrated in vitro against Candida albicans, $P$. anomala, Pneumocystis carinii, and Saccharomyces cerevisiae $(6,7)$. In addition, its potent antimicrobial effect was also demonstrated in vivo using a rat model of experimental pneumocystosis (6). 
Optimal WmKT activity is observed in acidic conditions ( $\mathrm{pH} 4.6)$ and at temperatures around $26-28{ }^{\circ} \mathrm{C}$. WmKT is specifically recognized by mAbKT4, a mouse monoclonal antibody (mAB) that neutralizes the killer activity of the toxin (8). Recently, anti-idiotypic antibodies displaying killer toxin activity (KTIdAbs) were produced by immunizing mice with mAbKT4. These KTIdAbs were shown to exert a lethal effect against the WmKTsensitive microorganisms $(9,10)$. Moreover, they were shown to be active against multidrug resistant isolates of Mycobacterium tuberculosis, as well as antibiotic-resistant Gram-positive cocci $(11,12)$. These results suggest that active WmKT derivatives (peptides or KTIdAbs) could be used for the development of new therapeutic or prophylactic strategies. Nevertheless, the molecular mechanism of the antibiotic effect of WmKT and KTIdAbs remains poorly understood and the targets of these killer molecules are not yet identified.

In a previous study, we described the purification and partial characterization of WmKT (13). WmKT was shown to be a $85-\mathrm{kDa}$ glycoprotein sharing structural similarities with yeast cell wall proteins suspected to exhibit glucosidase activity. We also demonstrated that soon after its binding to target cells, WmKT induces rapid cell permeation leading to death.

In the present study, we show that the killer activity of WmKT requires the interaction of the toxin with $\beta$-glucans present in the cell wall of sensitive cells. Moreover, we report data indicating that WmKT exhibits a $\beta$-glucosidase activity, which could explain the disruption of the cell wall integrity of sensitive cells exposed to WmKT, as demonstrated by scanning electron microscopy.

\section{Materials and Methods}

Yeast Strains, Growth Media, and Chemicals

W. saturnus var. mrakii MUCL 41968, which produces WmKT, was used as killer yeast strain, and P. anomala MUCL 41969 was used as WmKT-sensitive strain (5). Sabouraud broth (tryptone 5\%, meat peptone $5 \%$, dextrose $20 \%$ ) buffered at $\mathrm{pH} 4.6$ with $0.1 \mathrm{M}$ of citric acid and $0.2 \mathrm{M}$ of sodium phosphate was used as growth medium for killer toxin assays. Yeast minimal medium (YMM) buffered at $\mathrm{pH} 3.5$ with $25 \mathrm{mM}$ of citric acid was used to produce WmKT. Amphotericin B and zymolyase were purchased from Bristol-Myers Squibb (Paris, France) and ICN Pharmaceuticals Inc. (Costa Mesa, USA), respectively. Castanospermine and gluconolactone were from Sigma-Aldrich (Saint Quentin Fallavier, France).

\section{Spheroplast Production}

Approximately $10^{6}$ yeast cells from an overnight culture performed at $30^{\circ} \mathrm{C}$ in Sabouraud broth were successively washed with $1 \mathrm{ml}$ of physiologic water and $1 \mathrm{ml}$ of $1 \mathrm{M}$ sorbitol. The cells were then carefully resuspended in $10 \mathrm{ml}$ of $10 \mathrm{mM}$ phosphate buffer ( $\mathrm{pH}$ 7.5) containing $10 \mathrm{mM}$ EDTA, $1 \mathrm{M}$ sorbitol, $30 \mathrm{mM} \beta$-mercaptoethanol, and $30 \mu \mathrm{g} / \mathrm{ml}$ of zymolyase. The cell suspension was then stirred at $30 \mathrm{rpm}$ for $30 \mathrm{~min}$ at room temperature. After low speed centrifugations, the cells were resuspended in $1 \mathrm{ml}$ of $\mathrm{l} \mathrm{M}$ sorbitol.

\section{WmKT Purification}

WmKT was purified from the culture medium of W. saturnus var. mrakii MUCL 41968 as previously described (13). Briefly, a colony of W. saturnus var. mrakii MUCL 41968 was used to inoculate a 200-ml preculture in YMM. After $48 \mathrm{hr}$ of growth at $26{ }^{\circ} \mathrm{C}$ and $70 \mathrm{rpm}$, four flasks (2-liter volume) containing $450 \mathrm{ml}$ of YMM were seeded each with $50 \mathrm{ml}$ of preculture. After $15 \mathrm{hr}$ of growth at $26{ }^{\circ} \mathrm{C}$ and $70 \mathrm{rpm}$, yeast cells were harvested by centrifugation $(5000 \times \mathrm{g}$ for $10 \mathrm{~min}$ ), and the clarified supernatant was collected. After addition of 10 tablets of EDTA-free protease inhibitor cocktail (Complete, Roche, Mannheim, Germany), the spent growth medium corresponding to a volume of 2 liters was applied onto a Macro-Prep High S (Bio-Rad, Hercules, CA, USA) ion exchange chromatography column $(10 \times 2.5 \mathrm{~cm})$ equilibrated with $25 \mathrm{mM}$ sodium acetate (pH 3.5). After extensive washing with $25 \mathrm{mM}$ sodium acetate buffer ( $\mathrm{pH} 3.5)$, elution was achieved by passing $25 \mathrm{mM}$ sodium acetate buffer ( $\mathrm{pH} 4.6$ ) containing $1 \mathrm{M}$ of $\mathrm{NaCl}$. Eluted fractions containing purified WmKT were stored at $-80{ }^{\circ} \mathrm{C}$ until further use.

\section{Killer Toxin Activity Assays}

For the microassays, purified WmKT at various concentrations in $50 \mu \mathrm{l} 25 \mathrm{mM}$ sodium acetate buffer $(\mathrm{pH}$ 4.6) was mixed with $200 \mu \mathrm{l}$ of Sabouraud broth containing $5 \times 10^{4}$ P. anomala MUCL 41969 cells seeded into the wells of 96-well microplates (Costar, Brumath, France). The microplates were then incubated overnight at $26{ }^{\circ} \mathrm{C}$ and the growth of the killer toxin-sensitive strain was monitored by measuring the optical density at $630 \mathrm{~nm}\left(\mathrm{OD}_{630}\right)$ using an automatic plate recorder (Bio-tek Instruments, Inc, Winooski, Vermont, USA). Killer toxin activity was detected through growth inhibition of the sensitive strain compared to a toxin-free control microculture (14). Assays were performed in triplicate and the results expressed as average percent of growth inhibition \pm standard deviation compared to a WmKT-free control culture.

For the agar diffusion assays, perpendicular slots of approximately $100 \mu \mathrm{l}$ were made in the Sabouraud agar of plates seeded with P. anomala MUCL 41969. One hundred microliters of WmKT $(400 \mu \mathrm{g} / \mathrm{ml})$, amphotericin B $(8 \mu \mathrm{g} / \mathrm{ml})$, or zymolyase $(20 \mathrm{mg} / \mathrm{ml})$ solution were added to the slots and the Petri dishes were then incubated for $20 \mathrm{hr}$ at $26^{\circ} \mathrm{C}$.

To perform colony forming units (CFUs) assays, $10^{3}$ P. anomala MUCL 41969 cells were incubated for 
$5 \mathrm{hr}$ at $26{ }^{\circ} \mathrm{C}$ in $100 \mu \mathrm{l}$ of $25 \mathrm{mM}$ sodium acetate buffer (pH 4.6) containing $300 \mu \mathrm{g} / \mathrm{ml}$ of WmKT. Cells were then plated on solid Sabouraud medium. After $48 \mathrm{hr}$ of incubation at $26{ }^{\circ} \mathrm{C}$, CFUs were enumerated. Assays were performed in triplicate and the results expressed as average percent of CFUs \pm standard deviation compared to a culture with heated-inactivated WmKT.

\section{Hydrolytic Activity Measurement}

The hydrolytic activity of WmKT was assayed using $p$-nitrophenyl $\beta$-D-glucopyranoside, $p$-nitrophenyl $\alpha$-D-glucopyranoside, $p$-nitrophenyl $N$-acetylglucosaminide, or $p$-nitrophenyl $\alpha$-D-galactopyranoside (Sigma-Aldrich) as substrates. The assays were performed by incubating for $10 \mathrm{hr}$ at $26^{\circ} \mathrm{C}$ in $100 \mu \mathrm{l}$ of $25 \mathrm{mM}$ sodium acetate buffer ( $\mathrm{pH} 4.6$ ) containing $30 \mu \mathrm{g}$ of purified WmKT and $100 \mu \mathrm{l}$ of $1 \mathrm{mM}$ $p$-nitrophenyl-coupled substrate diluted in $25 \mathrm{mM}$ sodium acetate buffer ( $\mathrm{pH} 4.6$ ). Following incubation, the reaction was stopped by addition of five volumes of $1 \mathrm{M}$ sodium carbonate and $p$-nitrophenol release was quantified by measuring $\mathrm{OD}_{405}$. The results are expressed as the concentration of $p$-nitrophenol released per microgram of WmKT.

\section{Flow Cytometry Analysis}

Flow cytometry analysis were performed using a Coulter Epics XL flow cytometer (Coultronics, Margency, France). Propidium iodide (PI) fluorescence was collected through a $645-\mathrm{nm}$ dichroic band-pass filter after being reflected by a $620-\mathrm{nm}$ dichroic long pass filter. Before each analysis, 3 and $6 \mu \mathrm{m}$ green latex beads (Coultronics) were used to calibrate the light scatter and fluorescence parameters. To know whether WmKT activity was sensitive to $\beta$-glucosidase inhibitors, $40 \mu \mathrm{g}$ of WmKT in $100 \mu \mathrm{l}$ of $25 \mathrm{mM}$ acetate buffer ( $\mathrm{pH} 4.6$ ) were incubated for $1 \mathrm{hr}$ at $26{ }^{\circ} \mathrm{C}$ in the presence of gluconolactone or castanospermine. Then, $10^{6}$ overnight-grown $P$. anomala MUCL 41969 were added, and incubation at $26{ }^{\circ} \mathrm{C}$ was continued for $5 \mathrm{hr}$. The cells were harvested by centrifugation $\left(3000 \times \mathrm{g}\right.$ for $5 \mathrm{~min}$ at $\left.4{ }^{\circ} \mathrm{C}\right)$, washed twice with $1 \mathrm{ml}$ of PBS and resuspended in $1 \mathrm{ml}$ of PBS containing $10 \mu \mathrm{g} / \mathrm{ml}$ of PI (Sigma-Aldrich). The cell-associated fluorescence was determined by flow cytometry analysis of 10,000 cells.

\section{Scanning Electron Microscopy}

Overnight-grown P. anomala MUCL 41969 cells were numerated using a Thoma cell count chamber, and $10^{6}$ cells were incubated at $26^{\circ} \mathrm{C}$ for $5 \mathrm{hr}$ in the presence of $40 \mu \mathrm{g}$ of WmKT in $100 \mu \mathrm{l}$ of $25 \mathrm{mM}$ sodium acetate buffer ( $\mathrm{pH}$ 4.6). The cells were then collected by centrifugation, resuspended at a density of $10^{6}$ cells $/ \mathrm{ml}$ in PBS, and fixed for $5 \mathrm{hr}$ at room temperature in a $1.25 \%$ (v/v) glutaraldehyde solution prepared in $100 \mathrm{mM}$ sodium cacodylate buffer ( $\mathrm{pH}$ 7.0). After filtration through a $25-\mathrm{mm}$ diameter and $0.2-\mu \mathrm{m}$ porosity Anodisc (Whatman, Maidstone, UK), the cells were rinsed five times for 10 min with $25 \mathrm{ml}$ of cacodylate buffer. Post-fixation was performed for $3 \mathrm{hr}$ in a $1 \%$ $\mathrm{OsO}_{4}$ solution prepared in the cacodylate buffer, followed by five washes in ultrapure water. The samples underwent progressive dehydration by successive soaking in $50,70,95$, and $100 \%$ ethanol. Soaking in isopentyle acetate was performed before criticalpoint drying in $\mathrm{CO}_{2}$ using a EMDSCOPE CPD 750 apparatus. The filters were then attached to large scanning electron microscopy stubs and coated with gold-palladium by cathodic spreading in a Polaron E 5100 coater. Sample observations were performed using a JEOL JSM35CF scanning electron microscope operating at a voltage of $10 \mathrm{kV}$.

\section{Results}

\section{Interaction Between WmKT and Cell Wall $\beta$-Glucan}

WmKT, a killer toxin secreted by $W$. saturnus var. mrakii MUCL 41968, has been shown to bind to the surface of sensitive yeast cells. Because $\beta$-glucans represent the major constituent of the yeast cell wall and WmKT displays amino acid sequence similarities with yeast proteins suspected to be glucanases, we hypothesized that $\beta$-glucans of sensitive strains could act as receptors for WmKT. Using an agar diffusion assay, this hypothesis was first tested by investigating the effect of zymolyase and WmKT on the growth of the WmKT-sensitive P. anomala MUCL 41969 strain. As shown in Figure 1A, both WmKT and zymolyase inhibited the yeast growth. However, although 50 times more concentrated, zymolyase induced a growth inhibition weaker than that induced by WmKT, confirming the potent killer activity of this mycocin. Interestingly, zymolyase reduced the WmKT killer effect as demonstrated by

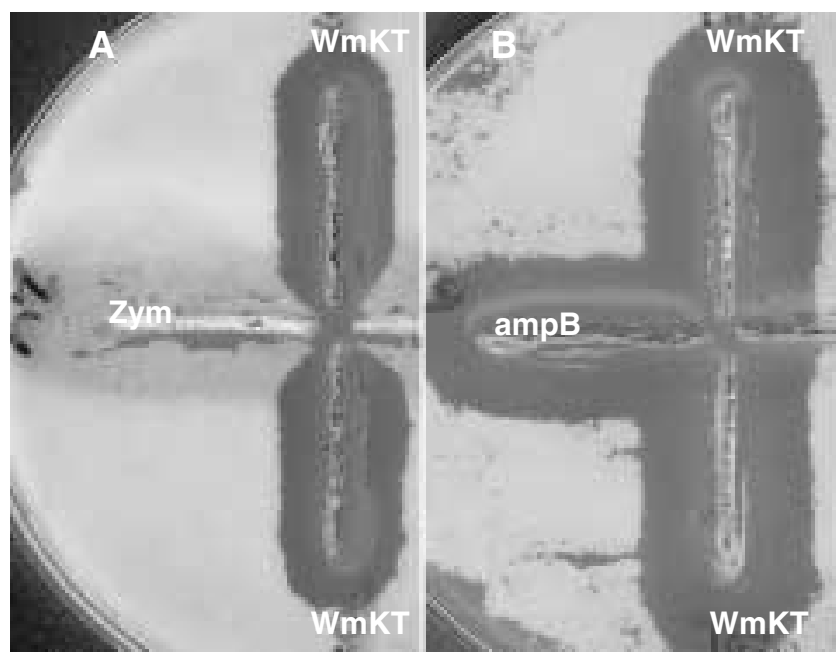

Fig. 1. Inhibitory effect of zymolyase on WmKT activity. Antifungal assays were performed using P. anomala MUCL 41969 cells grown in agar plates with perpendicular slots containing zymolyase (Zym), W. saturnus var. mrakii MUCL $41968(\mathrm{WmKT})$, or amphotericin B (ampB). The clear zones indicate $P$. anomala MUCL 41969 growth inhibition. 
the narrowed WmKT inhibition area at the vicinity of the slot containing zymolyase. This finding may indicate that intact $\beta$-glucans are required for WmKT activity.

The control experiment was performed using WmKT and amphotericin B, a fungicidal agent that does not degrade $\beta$-glucans, but acts on cell membrane ergosterol (Figure 1B). Both molecules induced similar growth inhibitions and no interference of amphotericin B with WmKT was observed.

Next, we investigated in a CFU assay the effect of WmKT on spheroplasts obtained after zymolyase treatment of a killer toxin sensitive yeast strain (P. anomala MUCL 41969). The spheroplasts were incubated for $5 \mathrm{hr}$ at $26{ }^{\circ} \mathrm{C}$ with $30 \mu \mathrm{g} / \mathrm{ml}$ of WmKT prior to plating on Sabouraud agar plates. Controls consisted in P. anomala MUCL 41969 intact cell incubated with WmKT or heat-inactivated WmKT, and $P$. anomala MUCL 41969 spheroplasts incubated with heat-inactivated WmKT. As shown in Figure 2, WmKT killed $75 \pm 1.8 \%$ of the intact cells but only $13 \pm 5.7 \%$ of the spheroplasts. These results indicate that zymolyase treatment of sensitive yeast cells reduces drastically the killing effect of WmKT, suggesting that intact $\beta 1,3$-glucan are required for the mycocin activity.

\section{Effect of Glycosidase Inhibitors on WmKT Killer Activity}

In a previous study, we reported the partial amino acid sequence of WmKT, which exhibits homologies with proteins belonging to the yeast SUN family $(13,15,16)$. Because some of these SUN proteins have been proposed to be glucosidases, we postulated that WmKT could act by hydrolyzing cell wall carbohydrate compounds. To test this hypothesis, we performed killing microassays in Sabouraud broth using $P$. anomala MUCL 41969 cells purified WmKT in presence of various concentrations of glucosidase inhibitors. As shown in Figure 3A, gluconolactone at concentrations ranging from 1-100 $\mathrm{mM}$ showed no inhibitory effect on the WmKT-induced killing. In contrast, castanospermine exhibited a very strong dose-dependent inhibitory effect; at $25 \mu \mathrm{M}$ the WmKT toxic activity was completely abolished (Figure 3B). Because castanospermine alone did not affect the growth of P. anomala MUCL 41969 (data not shown), it suggested that the specific $\beta$-glucosidase inhibitory effect of castanospermine was directly responsible for the abolition of the WmKT-induced yeast killing. Therefore, WmKT could be seen as a castanospermine-sensitive glucosidase and/or the WmKT glucan receptors are affected in their biosynthesis during the treatment with castanospermine.

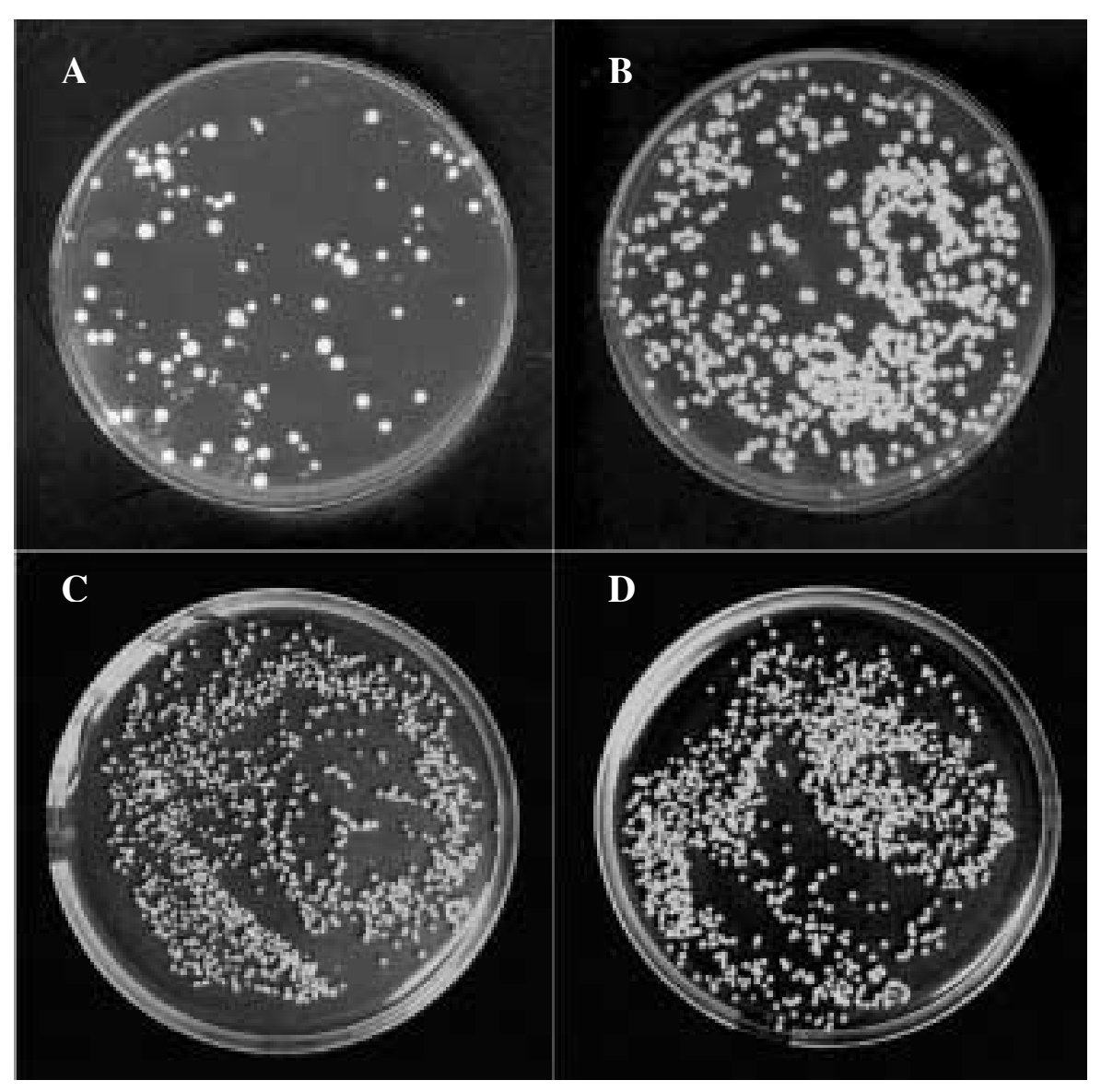

Fig. 2. Effect of WmKT on spheroplasts derived from a toxin-sensitive strain. Prior to seeding on Sabouraud medium, $10^{3}$ cells of the $P$. anomala MUCL 41969 sensitive strain were incubated for $5 \mathrm{hr}$ with WmKT (A) or with heat-inactivated WmKT (B) and $10^{3}$ spheroplasts of the same strain were incubated with WmKT (C) or with heatinactivated WmKT (D). CFUs were numerated after $18 \mathrm{hr}$ of growth at $37^{\circ} \mathrm{C}$. 
A

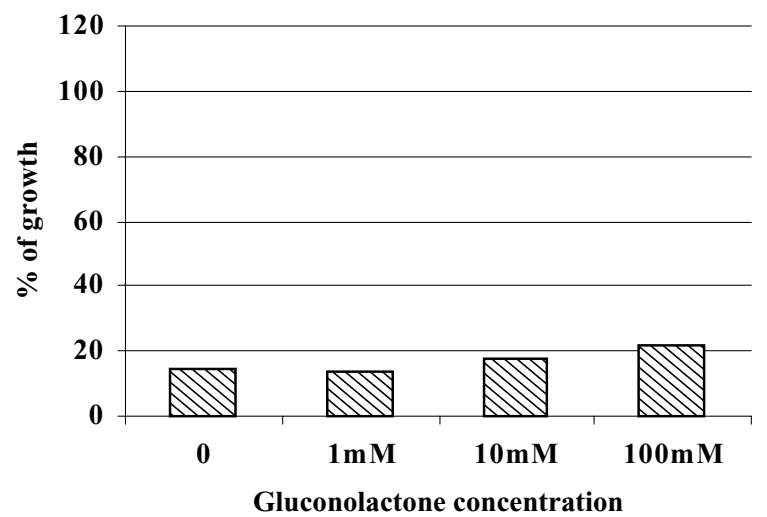

B

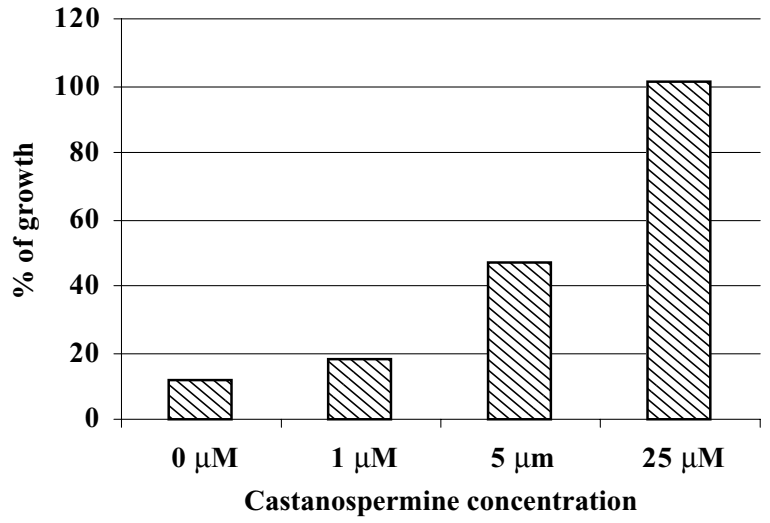

Fig. 3. Effect of the $\beta$-glucosidase inhibitors gluconolactone and castanospermine on the WmKT activity. P. anomala MUCL 41969 cells were incubated for $18 \mathrm{hr}$ at $26^{\circ} \mathrm{C}$ with $20 \mu \mathrm{g} / \mathrm{ml}$ of WmKT in the presence of various concentrations of gluconolactone (A) or castanospermine (B). The percent of growth of sensitive cells is indicated as the percent $\mathrm{OD}_{630}$ measured without toxin treatment.

To discriminate between these two possibilities, $100 \mu \mathrm{l}$ of WmKT at $300 \mu \mathrm{g} / \mathrm{ml}$ was incubated in the presence of $25 \mu \mathrm{M}$ of castanospermine. After $1 \mathrm{hr}$ of incubation at $26{ }^{\circ} \mathrm{C}$, WmKT was extensively dialyzed against $25 \mathrm{mM}$ sodium acetate buffer (pH 4.5), and added to P. anomala MUCL 41969 cells. Following a $5-\mathrm{hr}$ incubation at $26{ }^{\circ} \mathrm{C}$, the yeast cells were stained with PI and analyzed by flow cytometry for mortality (17). When the cells were treated with buffer alone or buffer containing $25 \mu \mathrm{M}$ of castanospermine, no significant PI labeling was observed, indicating an absence of cell mortality (Figures 4C and 4D). In contrast, a PI labeling of 73.4 $\pm 9.9 \%$ was observed following yeast treatment with WmKT (Figure 4A). Because this labeling was reduced to $17.9 \pm 3.8 \%$ when using castanosperminetreated WmKT, it suggested that WmKT may be a castanospermine-sensitive glucosidase (Figure 4B).

\section{Hydrolytic Activity of WmKT}

To address the hypothesis that WmKT may exhibit a glucosidase activity, purified WmKT was incubated with various potential carbohydrate substrates covalently linked to $p$-nitrophenyl, which cleavage can be monitored by spectrophotometry (18). No significant $p$-nitrophenol release was detected using $p$-nitrophenyl $\alpha$-D-glucopyranoside, $p$-nitrophenyl $N$-acetyl-glucosaminide, or $p$-nitrophenyl $\alpha$-D-galactopyranoside (data not shown). However, WmKT was shown to exert an hydrolytic activity against $p$-nitrophenol $\beta$-D-glucopyranoside (DNPG) (Figure 5A). Indeed, using $1 \mathrm{mM}$ of DNPG as substrate, $16.60 \pm 0.16 \mu \mathrm{M}$ of $p$-nitrophenol was released per microgram of purified WmKT over a 10-hr period. As shown in Figure 5A, this enzymatic activity was specifically inhibited by $25 \mu \mathrm{M}$ of castanospermine. Because this castanospermine concentration also inhibited the WmKT-induced killing of P. anomala MUCL 41969, it further suggested that WmKT exerts its toxic effect through glucosidase activity. No DNPG hydrolysis was detected using WmKT previously heated at $100{ }^{\circ} \mathrm{C}$ for $10 \mathrm{~min}$, confirming the reported thermolability of WmKT (19). Because WmKT was shown to be active in acidic conditions, $P$. anomala MUCL 41969 growth inhibition and DNPG hydrolysis assays were carried out at $\mathrm{pH} 4.6$ and $\mathrm{pH}$ 6.0. As shown in Figures 6A and 6B, a similar pH-dependence was demonstrated for growth inhibition and DNPG hydrolysis; both activities were reduced by approximately $55 \%$ when passing from $\mathrm{pH} 4.6$ to $\mathrm{pH}$ 6.0. Interestingly, purified WmKT incubated for $1 \mathrm{hr}$ at $\mathrm{pH} 6.0$ followed by dialysis against $25 \mu \mathrm{M}$ of sodium acetate buffer $(\mathrm{pH} \mathrm{4.6)}$ failed to induce $P$. anomala MUCL 41969 growth inhibition or DNPG hydrolysis (Figure 6C), indicating an irreversible lability of WmKT.

\section{Cell Wall Ultrastructure of Yeast Cells Treated With WmKT}

To know whether the WmKT treatment of P. anomala MUCL 41969 induces an ultrastructural modification, yeast cells incubated for $5 \mathrm{hr}$ at $26{ }^{\circ} \mathrm{C}$ in 100 $\mu \mathrm{l}$ of $25 \mathrm{mM}$ acetate buffer $(\mathrm{pH} 4.6)$ with $40 \mu \mathrm{g}$ of WmKT. P. anomala MUCL 41969 were observed by scanning electron microscopy. Compared to yeasts incubated in the absence of the mycocin (Figure 7A), the WmKT-treated $P$. anomala MUCL 41969 cells exhibited a rough surface that could be the result of partial degradation of the cell wall $\beta$-glucans (Figure 7B). To know whether such a phenotype was linked to glucan hydrolysis, $P$. anomala MUCL 41969 cells were treated for $5 \mathrm{hr}$ at $26{ }^{\circ} \mathrm{C}$ with $400 \mu \mathrm{g} / \mathrm{ml}$ of zymolyase. This treatment induced a surface phenotype (Figure 7C) similar to that observed with WmKT, suggesting that the WmKT toxic activity is due to the toxin's ability to hydrolyze the $\beta$-glucans present in the cell wall of sensitive yeast cells. This observation is in agreement with the WmKT-induced cell permeability demonstrated by the PI staining experiment. 


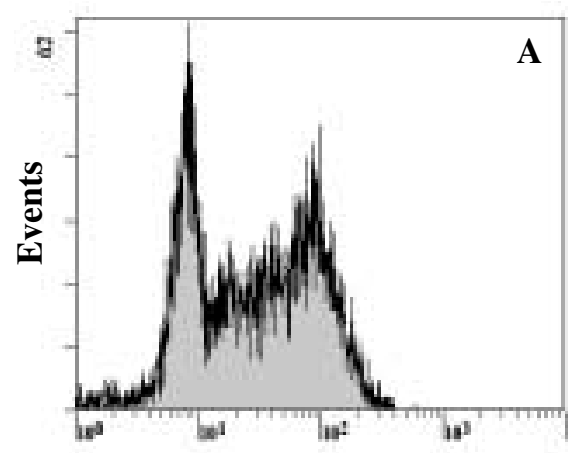

PI fluorescence

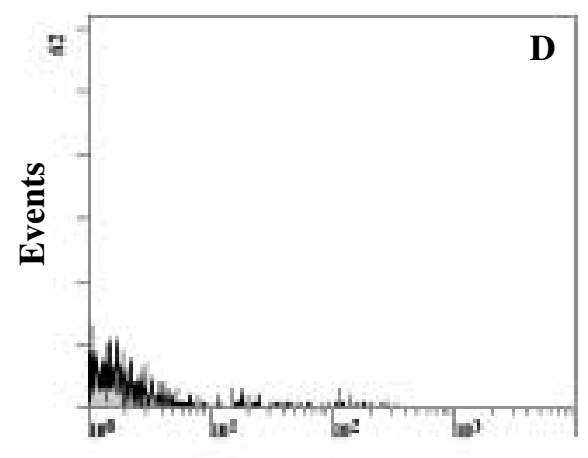

PI fluorescence

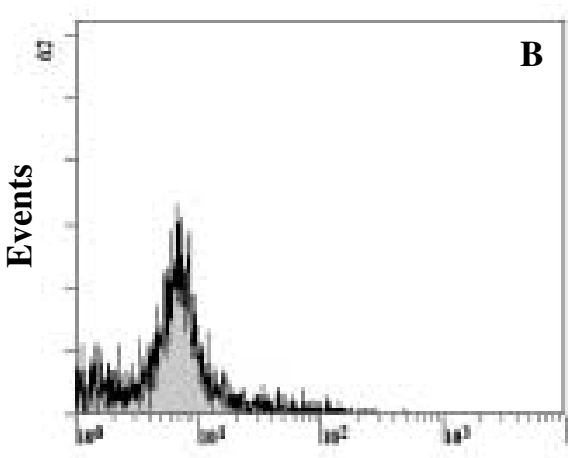

PI fluorescence

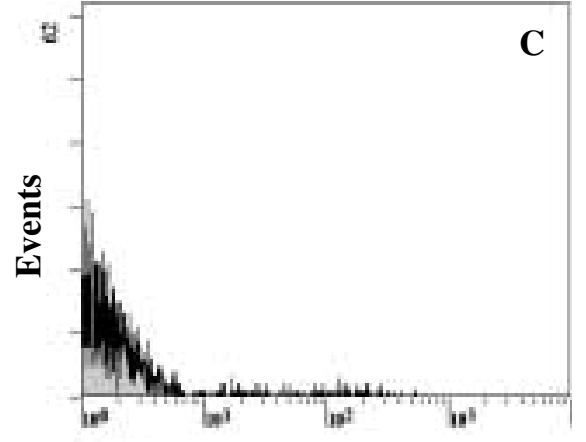

PI fluorescence

Fig. 4. Flow cytometry analysis of $P$. anomala MUCL 41969 cells stained with PI. Yeast cells $\left(10^{6}\right)$ were incubated for $1 \mathrm{hr}$ in the presence of $300 \mu \mathrm{g} / \mathrm{ml}$ of purified WmKT in $25 \mathrm{mM}$ of sodium acetate buffer $(\mathrm{pH} 4.6)(\mathrm{A}), 300 \mu \mathrm{g} / \mathrm{ml}$ of purified WmKT pretreated with $25 \mu \mathrm{M}$ castanospermine (B), buffer alone (C), or buffer containing $25 \mu \mathrm{M}$ castanospermine (D). After staining, cell-associated fluorescence was determined.

\section{Discussion}

The W. saturnus var. mrakii MUCL 41968 killer toxin is active against a wide range of infectious agents including $C$. albicans and $P$. carinii (3-5). Extensive studies reported that WmKT or WmKT-like antiidiotypic antibodies could represent new therapeutic molecules for the treatment of microbial infections (11,12,20-22). Despite all these studies, the molecular mechanism of WmKT-induced killing remains unknown. Recently, we purified WmKT to homogeneity and demonstrated that it is an $85-\mathrm{kDa}$ glycoprotein that induces rapid cell permeation (13). We hypothesized that WmKT could act by binding to $\beta$-glucan because a $S$. cerevisiae strain bearing a mutation in KRE1 (23), a gene involved in $\beta 1,6$-glucan synthesis, was resistant to the killer toxin, and a $S$. cerevisiae null mutant for KNR4 gene involved in $\beta 1,3$-glucan synthesis (24) was shown to be partially resistant to WmKT.

In this study, we report several observations that further support this hypothesis. First, we observed an antagonism between zymolyase, a mixture that hydrolyzes yeast cell wall glucans, and the WmKT activity, indicating that intact $\beta$-glucans are required for the WmKT-induced killing, and may therefore be the mycocin receptor. $\beta$-glucans as killer toxin receptors have already been described for a Pichia membranifaciens killer toxin (25), and for the $S$. cerevisiae $\mathrm{K} 1$ and K2 killer toxins (26) that bind to $\beta 1,6$-glucan. Moreover, $\beta 1,6-$ glucan and $\beta 1,3$-glucan were demonstrated to be the cell wall receptors of the Hansenula mrakii LKB 169 killer toxin (HM-1) (27). The requirement of $\beta$-glucans for WmKT activity is also supported by the fact that spheroplasts derived from $P$. anomala MUCL 41969 cells treated with zymolyase exhibited a strong resistance to $\mathrm{WmKT}$, confirming the requirement of $\beta$-glucans for the mycocin activity. Because the $S$. cerevisiae Kl killer toxin, which causes cell death through activation of Toklp potassium channel (28), only uses $\beta$-glucans as primary receptors and remains active against spheroplasts derived from sensitive cells (29), it suggests that $\beta$-glucans could be a major enzymatic target of WmKT and not simply a primary receptor.

Because the amino acid sequence analysis of WmKT revealed homologies with the yeast SUN proteins, a family of proteins including cell wall proteins suspected to be glucanases $(15,16)$, WmKT was investigated for potential hydrolytic activity that could result in hydrolysis of yeast cell wall $\beta$-glucans, and therefore explain the mycocin lethal activity. This was first tested using $\beta$-glucosidase inhibitors because such an enzyme inhibition strategy was successfully used to demonstrate that the chitinase activity of the Kluyveromyces lactis killer toxin is inhibitable by allosamidin, which leads to the abolition of the toxin lethal effect (30). When incubated with $P$. anomala MUCL 41969 in 


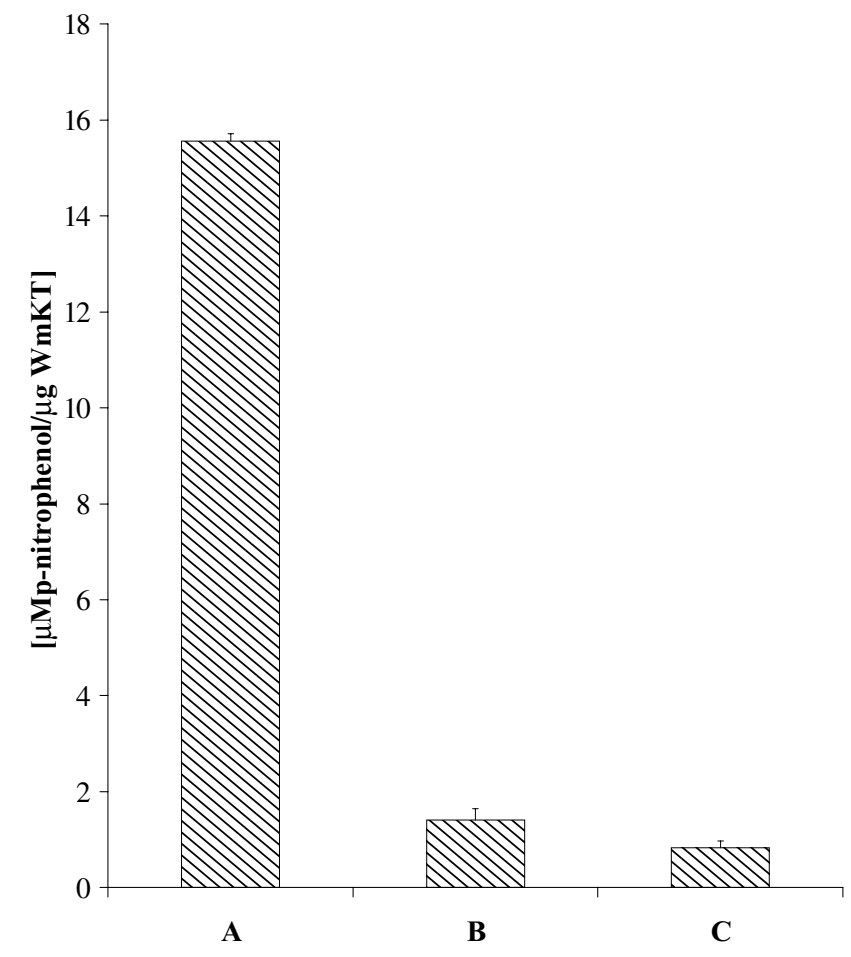

Fig. 5. Glucosidase activity of WmKT. Purified WmKT $(1.8 \mu \mathrm{g})$ in $50 \mu \mathrm{l} 25 \mathrm{mM}$ of sodium acetate $(\mathrm{pH} \mathrm{4.6)}$ was incubated for $10 \mathrm{hr}$ at $26{ }^{\circ} \mathrm{C}$ in the presence of $1 \mathrm{mM}$ of $p$ nitrophenyl $\beta$-D-glucopyranoside. The incubation was performed in the absence (A) or in the presence (B) of $25 \mu \mathrm{M}$ of castanospermine. The control experiment was performed using boiled WmKT (C). p-Nitrophenol release was monitored and expressed as micromoles of $p$-nitrophenol per microgram of WmKT. Means and standard deviations were calculated from three independent experiments.

the presence of the glucosidase inhibitor castanospermine, WmKT failed to kill yeast cells, suggesting that the killer toxin has glucosidase activity. Therefore WmKT may act by hydrolyzing the cell wall $\beta$-glucan, which are essential components for cell wall integrity.

The hydrolytic activity of WmKT was then investigated using various sugar substrates covalently linked to $p$-nitrophenyl. This in vitro enzymatic approach allowed us to show that purified WmKT is able to hydrolyze $p$-nitrophenyl $\beta$-D-glucopyranoside, but not $p$-nitrophenyl $\alpha$-D-glucopyranoside, p-nitrophenyl $N$-acetyl-glucosaminide, or $p$-nitrophenyl $\alpha$-D-galactopyranoside. This indicates that WmKT displays a castanospermine-sensitive $\beta$-glucosidase activity. These enzymatic assays also showed that WmKT exhibits a specific hydrolytic activity against DNPG. Such an activity has already been reported for some yeast exoglucanases that are more efficient against glucose polymers (31). We also show that the WmKT $\beta$-glucosidase activity and the WmKT killing effect exhibit exactly the same $\mathrm{pH}$ dependence, suggesting that the WmKT-induced lethality is linked to the enzymatic activity of the mycocin. According to this, WmKT would hydrolyze

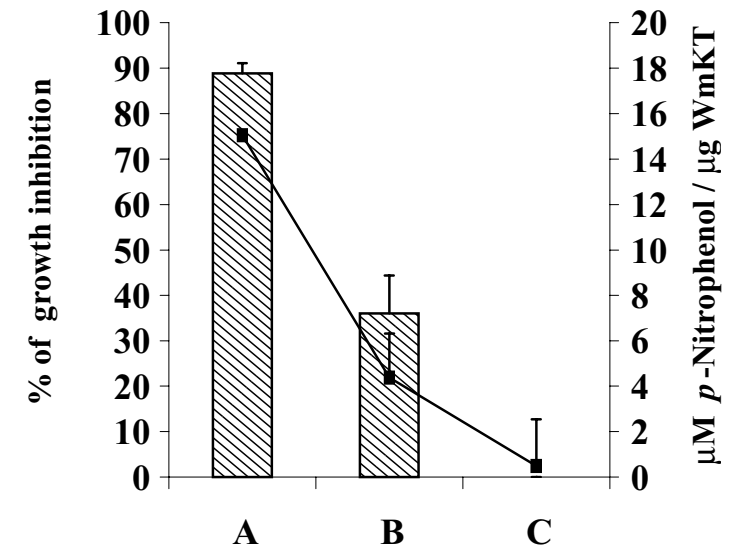

Fig. 6. Comparison of glucosidase and growth inhibition activities of WmKT. Growth inhibition (histograms) was measured as described in Material and Methods, and the glucosidase activity expressed in $\mu \mathrm{M}$ of $p$-nitrophenol released per microgram of WmKT (curve) was determined using $p$-nitrophenyl- $\beta$-D-glucopyranoside. Both assays were performed at $\mathrm{pH} 4.6$ (A) and pH 6.0 (B). (C) Results obtained using WmKT incubated at $\mathrm{pH} 6.0$ prior to acidification to $\mathrm{pH} 4.6$. Means and standard deviations were calculated from three independent experiments.

cell wall glucans present in sensitive cells. Comparable mechanisms have been described in plants and fungi that defend themselves against microbial invasion by producing $\beta$-glucanase (32-34). The hypothesis of a glucosidase activity associated with WmKT-induced killing is consistent with our previous observation showing that $W$. saturnus var. mrakii MUCL 41968 is resistant to zymolyase. The cell wall-degrading activity of WmKT was confirmed by scanning electron microscopy, which revealed that WmKT treatment of $P$. anomala 41969 leads to a rough cell surface. This effect is identical to that observed following treatment of the yeast cells with zymolyase. A similar effect on the cell wall morphology has recently been reported for the K2 killer toxin of $S$. cerevisiae that also binds to $\beta$-glucan, although its mechanism of action is still unknown $(35,36)$.

The results presented in this study constitute the first steps in the elucidation of the killing mechanism of WmKT. Further characterization of the WmKT enzymatic activity as well as the cloning of its encoding gene will represent the next investigation step toward a better understanding of this therapeutically promising yeast killer toxin but also of the molecules mimicking its activity such as KTIdAbs.

\section{Acknowledgments}

C. G. is supported by a Ph.D. grant from the Région Nord Pas-de-Calais (France) and the Institut Pasteur de Lille (France). E. D. is supported by a grant of the Catholic University of Lille, France. The Fondation pour la Recherche Médicale and FEDER funding granted this work. 

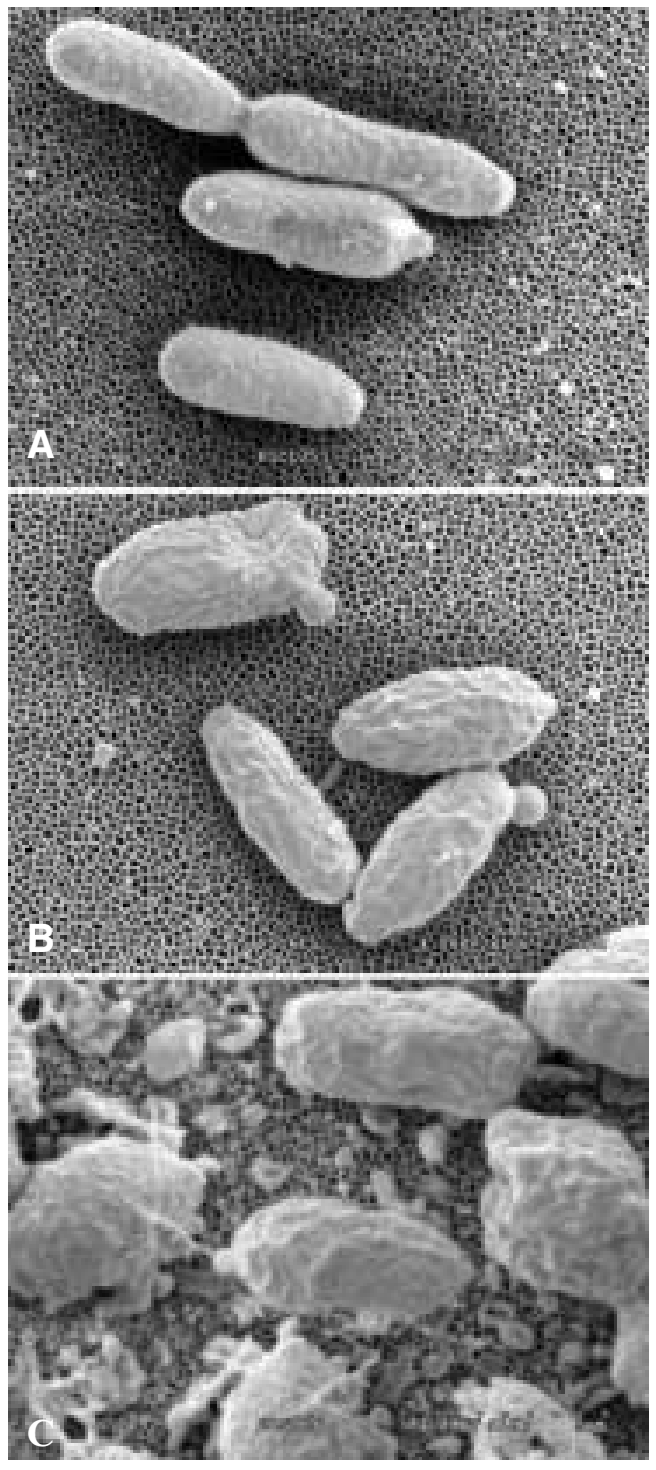

Fig. 7. Scanning electron microscopy analysis of $P$. anomala MUCL 41969 cells. Untreated cells (A) or cells treated for $5 \mathrm{hr}$ with $300 \mu \mathrm{g} / \mathrm{ml}$ of purified WmKT (B) or cells treated with $400 \mu \mathrm{g} / \mathrm{ml}$ zymolyase (C) were observed using a magnification of $10,000 \times$.

\section{References}

1. Cohen ML. (2000) Changing patterns of infectious disease. Nature 406: 762-767.

2. Ghannoum MA, Rice LB. (1999) Antifungal agents: mode of action, mechanisms of resistance, and correlation of these mechanisms with bacterial resistance. Clin. Microbiol. Rev. 12: 501-517.

3. Cailliez JC, Seguy N, Aliouat EM, Polonelli L, Camus D, DeiCas E. (1994) The yeast killer phenomenon: a hypothetical way to control Pneumocystis carinii pneumonia. Med. Hypotheses 43: 167-171.

4. Conti S, Magliani W, Gerloni M, et al. (1998) A transphyletic anti-infectious control strategy based on the killer phenomenon. FEMS Immunol. Med. Microbiol. 22: 151-161.

5. Guyard C, Evrard P, Corbisier-Colson AM, et al. (2001) Immuno-crossreactivity of an anti-Pichia anomala killer toxin monoclonal antibody with a Williopsis var. saturnus mrakii killer toxin. Medical Mycology 39: 395-400.
6. Seguy N, Cailliez JC, Polonelli L, Dei-Cas E, Camus D. (1996) Inhibitory effect of a Pichia anomala killer toxin on Pneumocystis carinii infectivity to the SCID mouse. Parasitol. Res. 82: 114-116.

7. Polonelli L, Morace G. (1986) Reevaluation of the yeast killer phenomenon. J. Clin. Microbiol. 24: 866-869.

8. Cailliez J, Cantelli C, Conti S, et al. (1993) Pichia anomala killer toxin secretion in the presence of tunicamycin. J. Med. Vet. Myc. 31: 337-342.

9. Seguy N, Polonelli L, Dei-Cas E, Cailliez JC. (1997) Monoclonal killer toxin-like antiidiotypic antibodies to control ratpneumocystosis. J. Eukaryot. Microbiol. 44: 37S.

10. Polonelli L, Seguy N, Conti S, et al. (1997) Monoclonal yeast killer toxin-like candidacidal anti-idiotypic antibodies. Clin. Diagn. Lab. Immunol. 4: 142-146.

11. Conti S, Fanti F, Magliani W, et al. (1998) Mycobactericidal activity of human natural, monoclonal, and recombinant yeast killer toxin-like antibodies. J. Infect. Dis. 177: 807-811.

12. Conti S, Magliani W, Arseni S, et al. (2000) In vitro activity of monoclonal and recombinant yeast killer toxin-like antibodies against antibiotic-resistant gram-positive cocci. Mol. Med. 6: 613-619.

13. Guyard C, Seguy N, Cailliez JC, et al. (2002) Characterization of a Williopsis saturnus var. mrakii high molecular weight secreted killer toxin with broad-spectrum antimicrobial activity. J. Antimicrob. Chemother. 49: 961-971.

14. Guyard C, Seguy N, Lange M, Ricard I, Polonelli L, Cailliez JC. (1999) First steps in the purification and characterization of a Pichia anomala killer toxin. J. Eukaryot. Microbiol. 46: 144S.

15. Skory CD, Freer SN. (1995) Cloning and characterization of a gene encoding a cell-bound, extracellular beta-glucosidase in the yeast Candida wickerhamii. Appl. Environ. Microbiol. 61: 518-525.

16. Mouassite M, Camougrand N, Schwob E, Demaison G, Laclau M, Guerin M. (2000) The 'SUN' family: yeast SUN4/SCW3 is involved in cell septation. Yeast 16: 905-919.

17. Green L, Petersen B, Steimel L, Haeber P, Current W. (1994) Rapid determination of antifungal activity by flow cytometry. J. Clin. Microbiol. 32: 1088-1091.

18. Lin J, Pillay B, Singh S. (1999) Purification and biochemical characteristics of beta-D-glucosidase from a thermophilic fungus, Thermomyces lanuginosus-SSBP. Biotechnol. Appl. Biochem. 30: 81-87.

19. Jackson HC, Seguy N, Killigin EM, Dei-Cas E, Polonelli L, Cailliez JC. (1996) Inhibitory effect of a Pichia anomala killer toxin on the viability of rat-derived Pneumocystis carinii. J. Eukaryot. Microbiol. 43: 29S.

20. Seguy N, Polonelli L, Conti S, Dei-Cas E, Camus D, Cailliez JC. (1996) In vitro decrease of rat-derived Pneumocystis carinii attachment induced by human natural yeast killer toxin-like antiidiotypic candidacidal antibodies. J. Eukaryot. Microbiol. 43: 27S.

21. Polonelli L, De Bernadis F, Conti S, et al. (1996) Human natural yeast killer toxin-like candidacidal antibodies. J. Immunol. 156: 1880-1885.

22. Beninati C, Oggioni MR, Boccanera M, et al. (2000) Therapy of mucosal candidiasis by expression of an anti-idiotype in human commensal bacteria. Nat. Biotechnol. 18: 1060-1064.

23. Boone C, Sommer SS, Hensel A, Bussey H. (1990) Yeast KRE genes provide evidence for a pathway of cell wall beta-glucan assembly. J. Cell Biol. 110: 1833-1843.

24. Hong Z, Mann P, Brown NH, et al. (1994) Cloning and characterization of KNR4, a yeast gene involved in $(1,3)$-beta-glucan synthesis. Mol. Cell Biol. 14: 1017-1025.

25. Santos A, Marquina D, Leal JA, Peinado JM. (2000) 1, 6beta-D-glucan as cell wall receptor for Pichia membranifaciens killer toxin. Appl. Environ. Microbiol. 66: 1809-1813.

26. Hutchins K, Bussey H. (1983) Cell wall receptor for yeast killer toxin: involvement of (1 leads to 6)-beta-D-glucan. $J$. Bacteriol. 154: 161-169.

27. Kasahara S, Ben Inoue S, Mio T, et al. (1994) Involvement of cell wall beta-glucan in the action of HM-1 killer toxin. FEBS Lett. 348: 27-32. 
28. Ahmed A, Sesti F, Ilan N, Shih TM, Sturley SL, Goldstein SA. (1999) A molecular target for viral killer toxin: TOK 1 potassium channels. Cell 99: 283-291.

29. Zhu H, Bussey H. (1989) The Kl toxin of Saccharomyces cerevisiae kills spheroplasts of many yeast species. Appl. Environ. Microbiol. 55: 2105-2107.

30. Butler AR, O'Donnell RW, Martin VJ, Gooday GW, Stark MJ. (1991) Kluyveromyces lactis toxin has an essential chitinase activity. Eur. J. Biochem. 199: 483-488.

31. Ridruejo JC, Munoz MD, Andaluz E, Larriba G. (1989) Inhibition of yeast exoglucanases by glucosidase inhibitors. Biochim. Biophys. Acta. 993: 179-185.

32. Stintzi A, Heitz T, Prasad V, et al. (1993) Plant "pathogenesisrelated" proteins and their role in defense against pathogens. Biochimie 75: 687-706.
33. Yi SY, Hwang BK. (1997) Purification and antifungal activity of a basic $34 \mathrm{kDa}$ beta-1,3- glucanase from soybean hypocotyls inoculated with Phytophthora sojae f. sp. glycines. Mol. Cells 7: 408-413.

34. Rey M, Delgado-Jarana J, Benitez T. (2001) Improved antifungal activity of a mutant of Trichoderma harzianum CECT 2413 which produces more extracellular proteins. Appl. Microbiol. Biotechnol. 55: 604-608.

35. Vadasz AS, Jagganath DB, Pretorius IS, Gupthar AS. (2000) Electron microscopy of the K2 killer effect of Saccharomyces cerevisiae T206 on a mesophilic wine yeast. Antonie Van Leeuwenhoek 78: 117-122.

36. Meskauskas A, Citavicius D. (1992) The K2-type killer toxinand immunity-encoding region from Saccharomyces cerevisiae: structure and expression in yeast. Gene 111: 135-139. 